\title{
O DUPLO FOCO DA GESTÃO DE MARCAS NAS REDES SOCIAIS
}

\author{
SABER ADMINISTRAR AS MARCAS NAS MÍDIAS SOCIAIS APARECE COMO \\ POTENCIAL FERRAMENTA PARA APROXIMAR AS ORGANIZAÇÕES DE SEUS \\ CONSUMIDORES E COLABORADORES. NO ENTANTO, É NECESSÁRIO IR \\ ALÉM DAS DEFINIÇÕES TECNOLÓGICAS E PENSAR ESTRATEGICAMENTE
}

| POR FELIPE ZAMBALDI + ANDRÉ OFENHEJM MASCARENHAS + FÁBIO MARTINS NATRIELI

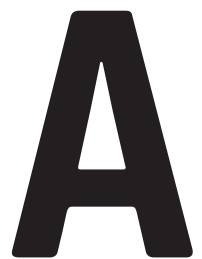
função do marketing evoluiu da criação de demanda por produtos para a gestão de mercados quando foram consolidados os conceitos de público-alvo, segmentação e posicionamento. Entretanto, a gestão de marcas permaneceu marginalizada até que a web 2.0 conectasse os mercados no ambiente das redes sociais virtuais.

Com a chegada dessas ferramentas, estabeleceu-se uma nova fase no modo como as empresas se relacionam com o mercado, já que propiciam meios para que consumidores dialoguem sobre serviços, produtos e marcas, influenciando a percepção da reputação das organizações. É aí que as mídias sociais ganham relevância estratégica, perante à necessidade das instituições exercerem influência sobre o que se fala a seu respeito em plataformas nas quais possuem controle limitado.

Esse fenômeno pode ser visto como uma ameaça por desafiar preceitos até então estabelecidos na gestão de marcas, exigindo que os gestores deixem a zona de conforto e tateiem áreas nas quais possuem pouco ou nenhum conhecimento. Mas o surgimento das redes sociais também pode trazer oportunidades às corporações, por permitir que se relacionem com seus clientes quase instantaneamente e com baixo custo.

\section{POTENCIAL ESTRATÉGICO} DAS MÍDIAS

Apesar dos benefícios, tirar vantagem das mídias sociais não tem sido tarefa fácil, como sugerem dois estudos publicados entre 2010 e 2012 . No primeiro, realizado pela Harvard Business Review, das 2.100 empresas entrevistadas, um terço (31\%) mede a efetividade desses canais e menos de um quarto (23\%) usa algum tipo de ferramenta para analisá-los. Contudo, os esforços parecem engatinhar, já que apenas $12 \%$ das instituições se consideraram usuárias ativas das redes, enquanto $7 \%$ estariam aptas a integrar apropriadamente as novas mídias às suas estratégias de marketing. 


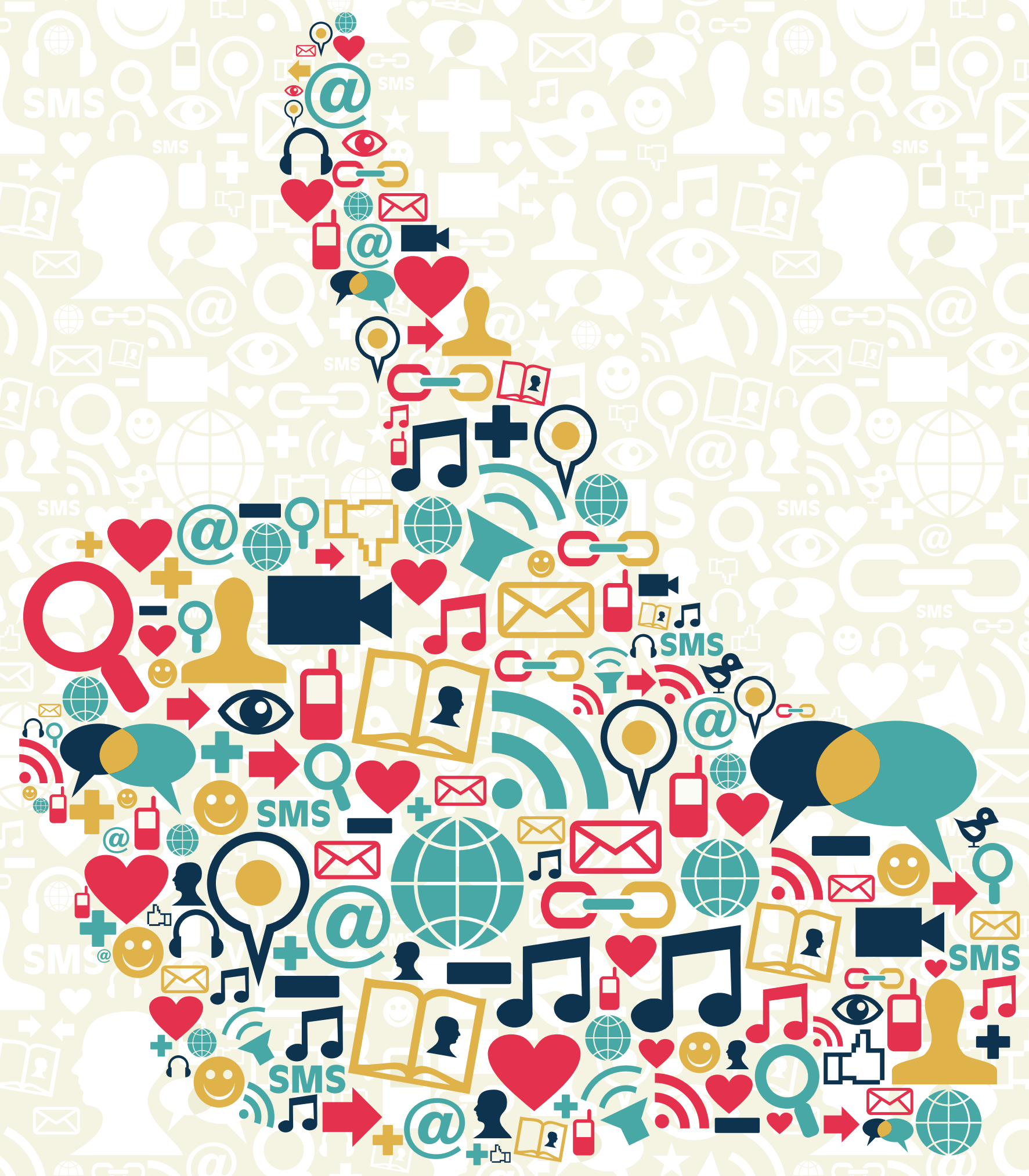


O segundo estudo, publicado pelo MIT - que conduziu a pesquisa abordando empresas de 24 indústrias em 115 países - revela que $80 \%$ dos gerentes compreendiam a importância das redes sociais como ferramenta de relacionamento e fonte de inovação. Contudo, poucas instituições possuíam uma estratégia para medir a efetividade de ações nas mídias sociais. Ambos os estudos refletem a dicotomia das redes sociais nas organizações: de um lado, o vasto potencial e entusiasmo dos líderes em incorporá-las em suas estratégias, do outro, a ausência de métricas que confirmem essa potencialidade.

\section{CONSUMIDORES NAS REDES SOCIAIS}

A primeira consequência desse fenômeno foi a necessidade das empresas encontrarem meios para dialogar com diversos grupos de consumidores na internet, seja por meio de blogues; fóruns; wikis; sites de revisões, como o TripAdvisor; canais multimídias, como o YouTube; e diversas redes sociais, como Facebook, Twitter, Tumblr e Pinterest. De repente, muitas corporações estavam ansiosas para interagir com seus clientes no Facebook, mas sem objetivo definido. Em geral, esse é o primeiro equívoco que elas cometem.

É comum que os gestores se preocupem mais com aspectos tecnológicos e menos com estratégia de comunicação, investindo recursos para suprir necessidades que julgam comuns às empresas e privilegiando as mídias sociais mais celebradas, como Facebook e Twitter. Ignoram, porém, o vasto e fértil campo da internet, bem como a presença e relevância de outros canais.

Enquanto a maioria das instituições usa parcialmente o potencial desses

\section{AS MÍDIAS SOCIAIS GANHAM RELEVÂNCIA ESTRATÉGICA DIANTE DA NECESSIDADE DAS ORGANIZAÇÕES SABEREM O QUE SE FALA A SEU RESPEITO EM PLATAFORMAS NAS QUAIS NÂO POSSUEM CONTROLE}

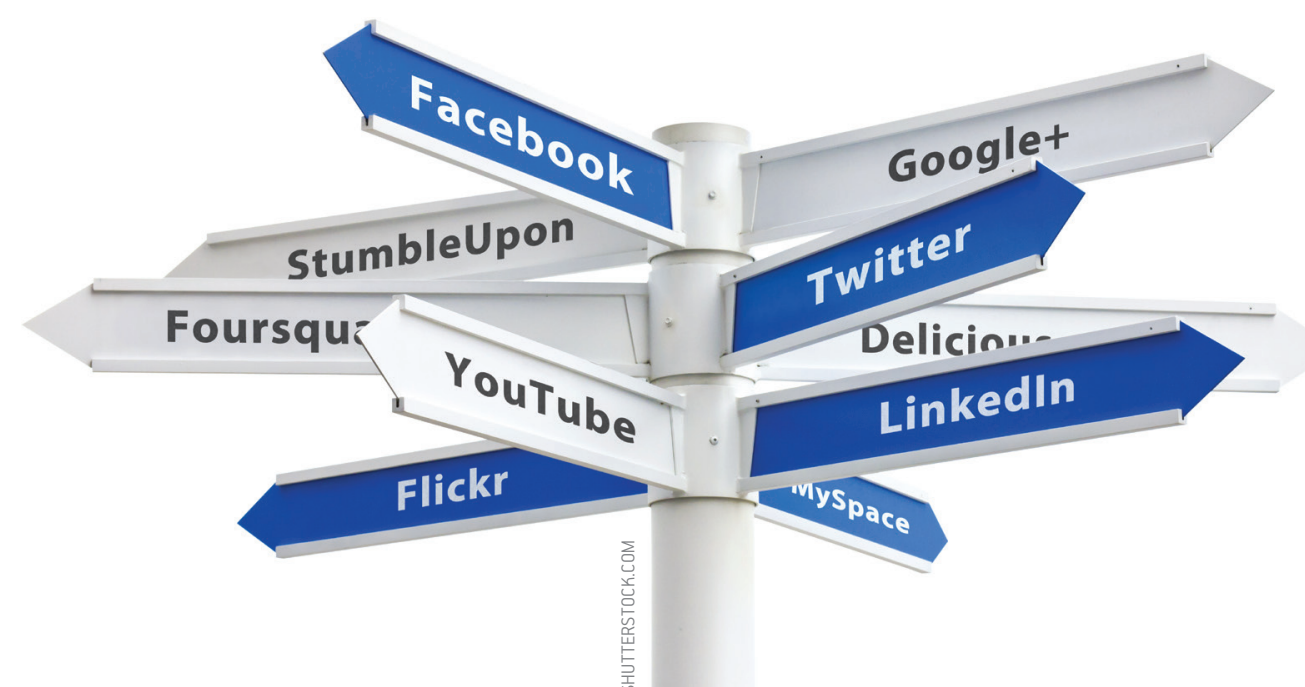

canais e enxerga o meio digital apenas como uma opção promocional, existem organizações que usam a tecnologia a seu favor e compreendem a complexidade dos ambientes virtuais, dos clientes e dos stakeholders. Assim, fica a dúvida: como as empresas têm usado as redes sociais para engajar consumidores na sua marca?

A Starbucks é reconhecida pelo uso eficaz dessas mídias, e, de fato, seus números impressionam. São 33 milhões de fãs no Facebook, 4 milhões de seguidores no Twitter e mais 1 milhão no Instagram, sem contar os acessos diretos no site da empresa. Todo esse universo está à disposição para receber postagens, tuítes, fotos de produtos e promoções. Mais do que a quantidade, é a qualidade da interação com o público que destaca a marca nas redes sociais.

Por exemplo, no ano passado, a Starbucks inglesa lançou uma promoção simples, com baixo custo e integrando várias plataformas - como Facebook, Twitter e Instagram - por meio de um concurso de fotos temáticas envolvendo um de seus produtos, o Frappuccino. As pessoas precisavam apenas tirar fotos diariamente sobre um determinado tema proposto pela empresa e incluir a hashtag \#MyFrappuccino antes de enviar a imagem pelo Twitter. Cada dia um participante era premiado com um cupom de dez libras para utilizar nas lojas da rede. Para convidar os primeiros consumidores a participar da promoção, foi necessário apenas o envio de um e-mail para a lista de endereços eletrônicos cadastrados espontaneamente. $\mathrm{O}$ resultado da ação ocorreu naturalmente, de forma viral. Com somente dez dias de duração, a campanha figurou entre os tópicos mais comentados do Twitter (trending topics) em várias localidades.

Em outro exemplo, mais recentemente, quando as luzes do estádio 


\section{INFORMAÇÕES GERADAS PELO PÚBLICO SERVEM DE BASE PARA A EMPRESA CRIAR CONTEÚDOS E TRAZER O CONSUMIDOR PARA PERTO}

Superdome se apagaram em Nova Orleans, durante a final do Super Bowl, em fevereiro deste ano, a Oreo, marca americana de biscoitos, destacou-se ao postar oportunamente em suas páginas no Twitter e no Facebook um anúncio que dizia: "Acabou a luz? Sem problemas! Você ainda pode mergulhar (Oreo) no leite no escuro". A mensagem repercutiu imediatamente nas redes sociais, com 15.000 retuítes e mais de 20.000 curtidas no Facebook. A empresa se planejou para agir nas mídias sociais durante a partida por saber que um terço da audiência estaria assistindo ao jogo conectado a um smartphone ou computador. A estratégia, além de imediata e eficaz, pode ser considerada de baixo custo, principalmente se comparada aos US\$ 4 milhões que podem ser cobrados por 30 segundos de anúncio na televisão durante o intervalo do Super Bowl.

\section{COLABORADORES NAS MÍDIAS SOCIAIS}

A ênfase da gestão de marcas está comumente no comportamento dos consumidores. Entretanto, recentemente, o foco nos colaboradores tem despertado a atenção de gestores e pesquisadores como forma de gerar vantagem competitiva sustentável para as instituições. A orientação para o mercado depende da sua difusão entre os colaboradores, o que implica a construção de capacidades internas coerentes que a favoreçam e confiram ênfase à orientação de mercado. A utilização dos recursos da empresa na criação de valores aos consumidores é um fator relevante à geração de capacidades que se manifestam em colaboradores comprometidos e satisfeitos com a organização. Essas são capacidades, em sua maioria, internas, como a gestão de pessoas e a cultura organizacional. Hoje, elas se apoiam nas relações de trabalho e podem ser entendidas como competências que resultam do bom marketing interno, orientação estratégica que visa implantar uma visão de mercado em toda a instituição.

Nesse cenário, gestores têm usado as tecnologias sociais em duas frentes: a primeira é influenciada por uma nova configuração no modo como as empresas recrutam e atraem candidatos, inserindo a tecnologia nas estruturas convencionais. Em tempos atuais, onde o conceito de emprego vitalício tornou-se obsoleto, os colaboradores não absorvem os valores da corporação naturalmente em processos de socialização graduais e de longo prazo. Esta era uma regra que hoje é exceção. A rotatividade de talentos é maior, e o mercado de trabalho tornou-se extremamente dinâmico. Contratare treinar constantemente novos funcionários são processos essenciais e custosos. A gestão de marcas ganha relevância porque muitas empresas terceirizam a produção e $\mathrm{o}$ atendimento.

Essa conjuntura demanda que gestores dediquem maior atenção ao conceito de employer brand, ou seja, benefícios funcionais, econômicos e psicológicos vinculados à marca e transmitidos aos seus colaboradores atuais e potenciais.

Redes sociais, como Facebook, Twitter e LinkedIn, são eficazes para a promoção da marca com objetivo de atrair, estimular e reter talentos. Empresas como Microsoft, Walt Disney, AT\&T, Walmart, Allianz, Ford Motor, General Motors, Nokia, UBS, BMW, GE, Basf, P\&G e Google, dentre outras, possuem páginas sobre carreiras no Facebook dedicadas exclusivamente a esse fim. Por meio dessas ferramentas, as organizações demonstram quais valores cultivam e permitem que seus colaboradores compartilhem histórias de sucesso, transformando-os em embaixadores da marca. Ao compartilhar publicamente sua cultura organizacional, a empresa assume uma identidade que, em tese, deve atrair e manter os candidatos que se identificam com ela.

A segunda é que, internamente, instituições também têm investido em redes sociais corporativas como instrumentos inovadores de gestão de pessoas. Das 500 empresas com melhor performance financeira listadas pela revista Forbes, $85 \%$ se valem de alguma plataforma social para uso interno. A tecnologia vem sendo um agente facilitador na conexão entre colaboradores em tempo real e de forma ordenada, promovendo novas configurações organizacionais, de forma a derrubar barreiras hierárquicas e departamentais. Seus principais benefícios são o incentivo à colaboração e ao engajamento, maior diálogo na companhia, compartilhamento de conhecimento e cultura, além da criação e apoio aos chamados embaixadores internos da marca.

\footnotetext{
FELIPE ZAMBALDI > Professor da FGV-EAESP felipe.zambaldi@fgv.br

ANDRÉ OFENHEJM MASCARENHAS > Professor do Centro Universitário da FEI > amascarenhas@fei.edu.br

FÁBIO MARTINS NATRIELI > Consultor e Mestrando do Centro
} Universitário da FEI > fnatrieli@gmail.com 